\title{
REINVERTIR EN LA HABANA: MERCANTILIZACIÓN DE LA VIVIENDA, Y GENTRIFICACIÓN EN LOS BARRIOS CÉNTRICOS DE UNA CIUDAD SOCIALISTA DEL SUR GLOBAL
}

\begin{abstract}
Violaine Jolivet es Profesora Asociada en la Universidad de Montreal. Su trabajo en geografía urbana y social se centra en los vínculos entre la movilidad y la producción urbana en América. Es autora del libro "Miami la Cubana, Geografía de una ciudad encrucijada entre las Américas" (publicado en francés en 2015) y ha publicado varios artículos sobre políticas de gentrificación y revitalización urbana bajo una perspectiva crítica en Miami, La Habana y Montreal.
\end{abstract}

Mateo Alba-Carmichael es geógrafo y cartógrafo de la Universidad de Montreal. En relación a Cuba, ha trabajado junto a Violaine Jolivet desde 2017 para el proyecto "(Re)investing Havana”, principalmente analizando y mapeando datos. También trabajó como pasante para el Grupo para el Desarrollo Integral de la Capital (GDIC) en La Habana en 2020. Sus intereses actuales incluyen el desarrollo social y regional de las ciudades, y el decrecimiento macroeconómico.

\section{Resumen}

Este artículo aborda la mercantilización de la vivienda en La Habana desde 2011 en adelante. Sustenta que las teorías de la gentrificación y del rent-gap pueden iluminar aspectos de la transformación de la capital cubana, aunque esas teorías fueron pensadas en contextos urbanos capitalistas y que la determinación del valor y la propiedad del suelo le corresponden en Cuba al Estado socialista. El análisis de los anuncios digitales de venta en cuatro plataformas entre 2012 y 2020 permite evaluar el precio y la ubicación de las propiedades a la venta, su relación con la reinversión económica en las áreas centrales de la ciudad y cómo los factores geográficos que definen la centralidad se ven cada vez más comprometidos por la turistificación y en general por la mercantilización de la vivienda. Las transformaciones urbanas estudiadas en este artículo pionero sobre el mercado inmobiliario y la gentrificación en la capital cubana permiten destacar, por 
un lado, que la transformación de la vivienda en una mercancía demuestra la erosión de los valores socialistas en la producción urbana y, por otro, que la creación de un mercado inmobiliario en La Habana ha reforzado la conexión de la ciudad cubana con las circulaciones transnacionales capitalistas.

El artículo considera el contexto económico y político en el que se forma este mercado, luego explica la metodología de big-small data en un contexto de acceso escaso a la información, seguido por un análisis caracterizando el mercado habanero que examina la importancia de la centralidad espacial y de los flujos transnacionales de personas y capital.

Palabras clave: vivienda, mercantilización, aburguesamiento, digitalización, ciudad post-socialista

En Cuba, desde noviembre de 2011, el decreto Ley-288 permite vender y comprar casas en la isla socialista para los ciudadanos cubanos, respetando una limitación establecida desde el principio de la Revolución Cubana de dos propiedades (principal y de veraneo) por individuo. Ese límite oficial protege bajo la ley el sector de la vivienda de una liberalización mercantil incontrolada que favorecería el papel de unos grandes propietarios o inversionistas (locales o extranjeros) que, en la mayoría de los mercados capitalistas o post-socialistas, son actores claves en la captación y acumulación de bienes raíces y, en particular desde las últimas décadas, de una financiarización del sector de la vivienda (Aalbers 2019). La formación de un mercado inmobiliario en La Habana permite ubicar el caso habanero entre los estudios sobre los mercados inmobiliarios emergentes pero también en el caso de las ciudades (post-) socialista ${ }^{1}$. En una isla donde $85 \%$ de la población es propietaria-ocupante y donde la especulación inmobiliaria y el crédito hipotecario fueron abolidos en las primeras horas de la revolución de 1959 (Trefftz 2011), la reintroducción, después de cincuenta años, de un mercado inmobiliario y de sus mecanismos socioeconómicos es un momento importante para testimoniar y analizar los cambios económicos y sociales más amplios que están sucediendo en la isla (Brenner et al. 2014; Pérez 2014; Pleyán 2020). La mercantilización de la vivienda es un dato relevante para entender las transformaciones orientadas al mercado dentro de la isla, así como la aceleración del proceso de privatización y liberalización en un Estado cuya última constitución, fechada en 2019, reafirma firmemente el carácter socialista del país.

1 Aunque incompleta, esta forma de categorizar las ciudades de países que han sido o siguen siendo gobernadas por regímenes comunistas designa una relación entre una entidad espacial específica: la ciudad y sus suburbios, y un sistema ideológico, político, económico y social: el socialismo. Algunas de las características de las ciudades socialistas son una gestión predominantemente pública del suelo y de las inversiones y una segregación socio-espacial reducida (French y Hamilton 1979; Szelenyi 1996; Hirt 2013). 
Las transformaciones urbanas estudiadas a partir del mercado inmobiliario en este artículo sobre La Habana demuestran, por lo tanto, una erosión de los valores socialistas de la producción urbana y testifican la amplificación de la conexión al capitalismo globalizado provocando una fragmentación de la ciudad y nuevas formas de capitalización a través de la vivienda que afectan al espacio urbano, diferencian el valor de suelo y transforman los barrios y con ello la vida cotidiana de los habitantes creando nuevas diferencias socio-espaciales en una ciudad considerada durante mucho tiempo "congelada" en el tiempo y en gran parte deteriorada. De esta manera, en relación con el tema de la fragmentación capitalista del espacio urbano (Lefebvre 1991) y como lo subraya C. Pleyán, este artículo trata de poner en evidencia las contradicciones de liberalizar la compra/venta del fondo construido en una ciudad socialista sin establecer previamente una ley de suelo porque «la propia localización de esa vivienda en una determinada ciudad y, dentro de ella, en una zona específica, independientemente de sus valores intrínsecos (materiales, fecha de construcción, etc.) incide en su valor (Pleyán 2020: 140).

Este estudio busca recordar que, al mismo tiempo que se devuelve a la vivienda un valor de cambio, muchas viviendas con necesidad de arreglos mayores no tienen otro valor que la del suelo (ubicación) y el precio estimado por cada individuo, en una ciudad donde la mayor parte de la población, si tiene o posee un techo, no está realmente en condiciones de invertir en una operación de compraventa, porque no dispone de medios económicos ${ }^{2}$ para mejorar sus condiciones actuales o porque no forma parte de sus prioridades diarias. De este modo, aunque las necesidades de vivienda son muy elevadas, ¿quiénes pueden participar o invertir en este mercado? El desarrollo del sector privado en la isla durante las últimas décadas que ha crecido de manera importante desde los lineamientos de 2011, reconocidos en la constitución de 2019, es uno de los cambios importantes identificados por varios expertos quienes resaltan la participación de la diáspora cubana en las economías domésticas y las inversiones (Hansing y Orozco 2014; Henken y Vignoli 2017; Wijburg et al., 2020). Otros análisis muestran que el mercado está formado por dos segmentos: (1) cubanos con una capacidad de inversión muy limitada por sus ingresos laborales pero que están en la necesidad de adquirir una propiedad básica para vivir, y (2) compradores cubanos, extranjeros o binacionales con un capital suficientemente alto como para mejorar su situación habitacional, o que buscan realizar una inversión inmobiliaria especulando un aumento de los precios o creando un negocio (Pleyán 2020).

2879 pesos cubanos (37 USD) es el salario medio mensual en 2020 según la estatal Oficina Nacional de Estadísticas (ONEI). En 2021, hay una reunificación monetaria interina aprobada en la Gaceta Oficial de Cuba, además el salario mínimo del país pasa a 2100 pesos cubanos mensuales (87 USD) (ONEI 2020) 
A partir de las reflexiones de H. Lefebvre (1991) sobre la producción del espacio y el derecho a la ciudad, la centralidad se concibe como una forma urbana pero también como la esencia de la condición urbana y critica la forma en que el capitalismo amenaza las dimensiones social y cultural de la centralidad. En este sentido, nuestra pregunta de investigación es la siguiente: ¿Cómo influye la centralidad urbana en el proceso de recapitalización de esta ciudad socialista sabiendo que la oposición entre el centro y la periferia había sido equilibrada por el proceso revolucionario? Nuestro enfoque en los barrios centrales concierne la cuestión de la gentrificación y de la turistificación, es decir a la transformación del espacio hacia el uso de los turistas en lugar de las necesidades de la población local, lo cual genera nuevas formas de desigualdades socio espaciales a través del proceso de mercantilización de la vivienda.

La primera parte del artículo presenta brevemente el marco teórico sobre la gentrificación (gentrification en inglés). Se presentará en una segunda parte el contexto de este estudio: las transformaciones económicas, legales y geopolíticas que caracterizan al nacimiento del mercado inmobiliario en La Habana. La tercera parte explica la metodología escogida y presenta nuestra base de datos de 7075 anuncios, explicando qué contiene y cómo se recolectó en un contexto de poco acceso a datos, movilizando el concepto de "Small Big Data". El análisis que viene a continuación presenta en una cuarta parte los precios de propiedades a la venta, sus características y la distribución de anuncios inmobiliarios entre 2012 y 2020, trataremos de caracterizar el mercado inmobiliario de La Habana y la distribución de los precios en la ciudad que resalta una fuerte oposición entre el centro y las periferias de la ciudad que permite destacar unos procesos de aburguesamiento. La quinta parte, retomará la cuestión de la centralidad en el valor mercantil de la vivienda y mostrará cómo los barrios centrales se ven más afectados por la actividad inmobiliaria no solo por la cuestión de calidad del espacio construido, sino también por el potencial del valor de suelo. La última parte cuestionará el efecto de los lugares conectados al capitalismo global como los espacios turísticos (estatales y privados) y de las zonas patrimoniales sobre el mercado inmobiliario, no solo para espacializar unos "puntos calientes", sino también para poner de relieve que lo que se comercializa a través de la compra/venta de vivienda no es sólo la centralidad, sino también el usufructo o el servicio producido por el uso de la vivienda.

\section{Situando a La Habana en los Estudios sobre la Gentrificación}

La gentrificación implica un cambio de población que consiste en el desplazamiento/ sustitución de la población existente por nuevos usuarios o habitantes con características socioeconómicas superiores a las de los antiguos usuarios y residentes. Estos cambios de población van acompañados de una transformación del espacio 
público y comercial y del entorno construido mediante la renovación y la reinversión de capital en barrios populares o donde previamente se dejó de invertir. A pesar de los orígenes en el Norte Global de dicha teoría, nos parece importante, siguiendo a Loretta Lees y sus colegas (2016), considerar que la gentrificación es un concepto ahora global y se puede aplicar a una ciudad como La Habana. La literatura sobre la gentrificación es ahora muy amplia. Las escuelas de pensamiento clásicas en este campo se han distinguido por las explicaciones causales basadas en la transformación de las clases medias y sus gustos (Ley 1996), por un lado, y por otro, se centra más en los modos de producción de la ciudad y la transformación de la oferta por parte de las dinámicas capitalistas (Smith 1987, 2002). Aunque los dos enfoques son complementarios y que estamos de acuerdo con la idea de que no hay un único proceso causal el anclaje teórico de este estudio, se sustenta que en los estudios sobre el aburguesamiento, las teorías de la centralización del capital y del diferencial de renta (o rent-gap en inglés) pueden iluminar aspectos particulares de la transformación urbana en la capital cubana y detectar ciertos peligros asociados a modificaciones importantes en cuanto al acceso al suelo y la vivienda y con la consecuencia de eventuales desplazamientos o exclusiones residenciales (López-Morales 2015).

El rent-gap se basa en un análisis marxista de los procesos de producción urbana; destaca que la gentrificación sucede cuando el valor actual del suelo o de la propiedad es inferior a su valor potencial. Esto motiva el proceso de regreso del capital o reinversión en ciertas zonas de la ciudad, donde se pueden maximizar las plusvalías (Smith 1979, 1987; Slater 2017), porque tuvieron un periodo de desinversión, donde las rentas del suelo y el precio de los edificios disminuyeron. En un caso como el habanero, donde la determinación del valor y la propiedad del suelo quedaron fuera del sector y los intereses privados desde los primeros años de la revolución, nuestro análisis intenta caracterizar el papel que juegan la centralidad urbana (determinada por la concentración de la actividad económica, cultural y turística) y el Estado (Hackworth y Smith 2001) en la fijación del precio inmobiliario. En este artículo también tratamos de verificar la utilidad de estudios sobre la gentrificación aplicados a un contexto específico: una ciudad socialista del Sur Global.

Los trabajos realizados por geógrafos urbanos en ciudades del antiguo bloque soviético, entre otros, han mostrado cómo la reintroducción de la propiedad privada, la llegada de operaciones inmobiliarias lideradas por asociaciones público-privadas y la apertura de la fábrica urbana hacia actores internacionales han transformado las ciudades y han provocado el crecimiento de nuevas segregaciones socio-espaciales (Rudolph y Brade 2005; Stanilov 2007; Sýkora 2009; Andrusz et al. 2011). Los trabajos sobre las ciudades post-socialistas también han puesto de manifiesto un proceso de aburguesamiento, aunque este no 
se desarrolló de la misma manera que en ciudades del hemisferio occidental capitalistas. A menudo se ha destacado la importancia de tener en cuenta las otras temporalidades urbanas que caracterizan a las ciudades post-socialistas y la especificidad del control de los diferentes actores en la reconquista urbana (Kubeš y Kovács 2020).

Asimismo, las observaciones en contextos post-socialistas europeos sobre otras temporalidades son similares, en diferentes contextos, a aquellas descritas en parte de la literatura sobre los procesos de gentrificación y renovación urbana en las ciudades del Sur Global. Los estudios asiáticos (Shin et al. 2016) y latinoamericanos (López-Morales et al. 2016) permiten destacar la diversidad de contextos en los que se produce una reinversión en los centros de las ciudades, pero sobre todo permiten percibir la complejidad de los procesos involucrados. Esto con el objetivo de simplemente de poner en relieve las especificidades de las desigualdades socio-espaciales y las relaciones de poder en las metrópolis del Sur, siendo necesario no generalizar procesos urbanos distintivos bajo la misma etiqueta de gentrificación (Lopes de Souza 2016). Algunos investigadores insisten en la especificidad de este concepto, originado en las ciudades globales del Norte y que no corresponde necesariamente con los planteamientos de las ciudades poscoloniales (Maloutas 2017).

En La Habana se pueden diferenciar dos tipos de procesos a los que se les puede dar la connotación de aburguesamiento, aunque sea un fenómeno emergente. Por una parte, la emergencia de un grupo con acceso a capital (a través de familias transnacionales con remesas y el desarrollo del cuentapropismo) y la facilitación de compra por medio de la liberalización del mercado inmobiliario ha permitido una movilidad residencial de familias con mayor poder adquisitivo que reemplazan hogares más humildes, en particular en los municipios centrales que históricamente eran los lugares de residencia de la clase media y alta antes de la Revolución como el Vedado, Playa, o Miramar. Las poblaciones reemplazadas se mudan a otros barrios peri-centrales o suburbanos. Por otra parte, también se da una gentrificación vinculada con la economía del turismo habanero que juega un papel importante en el aburguesamiento de ciertos barrios centrales, donde las familias residentes son reemplazadas por propietarios que desean destinar los espacios para la renta a turistas extranjeros (Witjburg et al. 2020). Este fenómeno es evidente en la Habana Vieja donde se utiliza también como argumento de venta el alto valor patrimonial del barrio (clasificado como patrimonio mundial por la UNESCO) y el desarrollo turístico de la zona. Los procesos de turistificación y la valorización patrimonial permiten ubicar también La Habana entre los estudios sobre gentrificación y turismo en una perspectiva internacional (Gravari-Barbas y Guinand 2017). De hecho, desde los 2000, investigaciones realizadas en La Habana Vieja evidencian una "capitalización" por parte del Estado a través de 
áreas prioritarias para el desarrollo turístico (Rutheiser 2000; Hill 2007; Herrero 2007) y han permitido cuestionar la nueva relación de la ciudad cubana con la globalización y la mercantilización (Edge et al. 2006; Bailey 2008). Los autores describen una ciudad con crecientes desigualdades, sobre todo debido a la existencia, desde mediados de los años 1990, de una economía dual con la creación del peso convertible, o CUC, indexado al dólar estadounidense, introducido sobre todo en las zonas turísticas, y además al fuerte aumento de las transferencias de dinero y bienes de consumo enviados desde fuera de la isla. En consecuencia, existen importantes desigualdades entre los cubanos que tienen acceso a estos circuitos económicos vinculados al turismo y a la economía global y aquellos que no cuentan con estas relaciones transnacionales (Scarpaci et al. 2002). Más recientemente, el artículo de Wijburg, Aalbers y Bono (2020) sitúa el caso de La Habana en el análisis de mercados emergentes y procesos de mercantilización y financiarización, resaltando el peso de las dinámicas transnacionales.

\section{Reformas hacia el mercado en Cuba y contexto de la mercantilización de la vivienda}

El Estado cubano se enfrentó a una verdadera crisis de la vivienda desde los primeros días de la revolución mientras se ponían en marcha varias políticas para hacer frente a esta carencia, desde el aumento de materiales de construcción prefabricados (1960-1970), la experiencia de autoconstrucción llevada a cabo por las microbrigadas (1970-1980), hasta la entrega de recursos para los hogares afectados por huracanes o la creación de vivienda social y de cooperativas habitacionales (Trefftz 2011; Rabinovich 2010; Rego 2018). A pesar de que el $85 \%$ de los cubanos son propietarios de una vivienda y, que por lo tanto, pudieran participar potencialmente en el mercado, esto no elimina el hecho de que el mercado inmobiliario naciente se desarrolla en un contexto de crisis de la vivienda. La situación de la vivienda es un desafío grande en la isla y en particular en La Habana desde hace varias décadas (Rego 2018). Aunque el Estado revolucionario ha impulsado la construcción de cientos de miles de viviendas desde 1960, siempre la tasa de construcción ha sido menor que la tasa de crecimiento poblacional (Mesa-Lago 2017). La Habana con 2,1 millones de ciudadanos, "tiene una situación todavía más difícil” (Pleyán 2020: 137). En la capital, donde la gran mayoría de los edificios se construyeron antes de la Revolución y han tenido pocos arreglos, muchas viviendas están en mala condición e incumplen de una forma u otra con los códigos urbanos (Iñiguez 2014; Pleyán 2020).

Nuestra investigación se centra en los municipios centrales de La Habana Vieja, Centro Habana, Playa y Plaza de la Revolución, estos municipios se 
caracterizan por densidades edilicias y de población muy altas y por construcciones bastante antiguas con alto valor patrimonial, especialmente en los barrios coloniales de Centro Habana y en La Habana Vieja ${ }^{3}$. Esto complica las intervenciones o reparaciones, por encima de las grandes dificultades de encontrar no solo los materiales a buen precio sino también la mano de obra, aunque el Estado ha facilitado recientemente las modalidades de auto-reparación liberalizando en parte las obras de construcción (Mesa-Lago 2017). El suministro de cemento y otros materiales básicos de construcción sigue siendo complicado, en parte debido al embargo impuesto por Estados Unidos desde 1962.

\section{Cuba post-1989, una lenta y heterogénea apertura económica hacia el mercado}

La apertura de un mercado inmobiliario refleja un contexto de cambio en la isla, y aunque los nuevos procesos liberalización y la privatización sean más visibles desde la década del 2010, estos procesos están arraigados con los cambios políticos y económicos que se han producido desde los años 90 como el colapso del bloque socialista y la necesidad del Estado cubano de sobrevivir económicamente tras la desaparición de la URSS, su principal socio comercial, en un contexto de embargos comerciales y financieros impuestos desde 1962 por su poderoso vecino del norte. La apertura económica no se puede entender sin este contexto geopolítico primordial: una isla que lleva casi 60 años bajo embargo económico de EEUU (Jolivet 2017).

La literatura sobre las transiciones hacia la economía capitalista en los países socialistas ha destacado en gran medida la "lentitud" de la apertura cubana hacia una economía de mercado y los propios límites conceptuales de la noción de transición (Whitehead y Hoffman 2016). La transformación de la economía cubana y su apertura al capitalismo globalizado ha sido más tímida que las experiencias de Vietnam o de China que a partir de los años ochenta y noventa afirmaron una permanencia política e institucional (con un partido único y unas formalidades de gobierno sustancialmente idénticas) pero una conexión a la economía mundial a pasos forzados (Scarpaci 2000; Mesa-Lago 2013; Vidal 2016). Ciertamente, los años 90 en Cuba, que corresponden al Periodo especial en tiempo de paz, fueron un periodo de profunda crisis para el país, tiempos que impidieron transformaciones estructurales y reorientaron el desarrollo económico hacia sectores

3 En 2016 la densidad de población en el municipio de Centro Habana era de 40368 hab $/ \mathrm{km}^{2}$ (lo cual es altísimo para el Caribe) en la Habana Vieja de $19298 \mathrm{hab} / \mathrm{km}^{2}$, en Playa de 5044 hab/km² y en Plaza de la Revolución de 11883 hab/km² (ONEI 2017). 
específicos. La apertura al turismo de masas, el desarrollo de la biotecnología, el nacimiento de empresas mixtas (surgiendo de asociaciones entre empresas extranjeras y el Estado cubano) para generar inversiones, el surgimiento de la pequeña empresa privada y la creación del CUC indexado al dólarestadounidense, fueron unas de las iniciativas tomadas en un momento en que el embargo se reforzó de nuevo con la Ley Torricelli (1992), que pretendía frenar el crecimiento de los nuevos motores de la economía cubana. El sistema económico de doble moneda, que llegó a fin al entrar al año 2021, fue una de las medidas largamente criticadas por haber creado dos circuitos económicos y haber ampliado las desigualdades entre los cubanos que tienen acceso a esta divisa (remesas, trabajo en sectores específicos como el turismo o la pequeña empresa privada) y los demás (Holbraad 2017; Bastian 2018).

\section{La actualización del modelo cubano}

El traspaso del poder entre los hermanos Castro en 2008 coincidió con una aceleración de las reformas económicas sin abandonar el modelo socialista. Los académicos y expertos dentro como fuera de la isla destacaron una diversificación de los actores y los motores del crecimiento económico durante la década 2000 que se refuerza con los lineamientos de 2011 (Sánchez Egozcue y Triana 2008; Brenner et al. 2014; Bobes et al. 2015). Como lo indica el economista cubano Triana, pueden distinguirse tres líneas de acción hacia la "actualización” del país:

- La transición horizontal de la economía a través de la creación de cooperativas y la privatización parcial de varios sectores de la economía (en particular la economía urbana).

- La “reestructuración y modernización del aparato estatal” a través de procesos de descentralización y transformaciones de varios ministerios.

- "La erradicación de prohibiciones" comerciales, lo cual incluye un mejoramiento de las telecomunicaciones (incluso del internet) en la isla, la creación de un mercado privado de automóviles [importados] y la creación de un mercado privado de viviendas, lo que, junto con transformaciones en las normas migratorias, debe contribuir a la mejora de la situación de la población (Triana 2012: 86-7).

Los lineamientos y las leyes posteriores no sólo aumentaron la cantidad y los sectores en los que son concedidas licencias a cuentapropistas - eufemismo para "empresarios" - y reformaron la reglamentación acerca de las inversiones extranjeras, sino que también validan la liberalización del mercado inmobiliario (Hamberg 2012; Pleyán 2020). El derecho a comprar y vender su casa ahora se 
incluye en la Constitución cubana de 2019 aceptada por el presidente DíazCanel. En esta investigación, las modalidades de las modificaciones en 2011 de la Ley general de la vivienda, conocida como el Decreto-Ley 288, y las transformaciones de los instrumentos fiscales en 2017 en Decreto Ley 343 (que precisan cuál es el valor referencial de la vivienda para aplicar la tributación 4\%), fueron los instrumentos legales de la actualización más movilizados para entender el contexto de la economía política que enmarca el nacimiento del mercado inmobiliario habanero.

Cabe mencionar que la actualización de las leyes de vivienda para autorizar la compra y venta inmobiliaria surge de una necesidad creciente de facilitar el cambio de hogares entre familias. Esta demanda fue inicialmente afrontada por las leyes de permuta de vivienda entre familias, sin embargo, existía también una "necesidad" de transacciones monetarias que eran ilegales en el contexto de la permuta (Núñez 2008). Por lo tanto, un aspecto primordial de la razón de la autorización de la compra y venta es de intentar controlar las transacciones ilegales que se estaban realizando de manera anteriormente por medio de la permuta de viviendas (Pleyán 2020). La intención anunciada no es la de crear un ámbito propicio para inversores, el mercado de inversión inmobiliaria es una consecuencia ineludible de esta liberalización parcial de este sector de la economía.

\section{Conexión transnacional y su impacto en la apertura económica}

A esos cambios de actualización interna se debe unir el contexto geopolítico. La alianza con Venezuela ${ }^{4}$, la formación de la coalición económica de la ALBA (Alianza Bolivariana para los Pueblos de Nuestra América), pero también la creciente participación de China en el comercio exterior y la inversión extranjera (Mesa-Lago y Vidal 2019) fueron a partir de los 2000 transformando la geografía relacional de Cuba (Jolivet 2017). Las nuevas circulaciones transnacionales con Estados Unidos son también un aspecto importante para entender las nuevas formas de conexión de la isla con el exterior, y el papel de la diáspora en la constitución de un campo transnacional cubano (Bobes et al. 2015).

La transición del poder a Raúl Castro, así como la llegada de los demócratas a la Casa Blanca en 2008, mejoraron las condiciones de viaje de las familias

4 En 2017 Cuba tuvo un intercambio comercial con Venezuela representando cerca del 12 por ciento del Producto Interno Bruto (PIB). Como lo nota Jimenez Enoa (2019), a partir de este año, en que se refuerza el embargo de los EEUU y la crisis en Venezuela, disminuyen a la mitad los barriles de petróleo que llegaban desde 2002 a Cuba de Venezuela. Una de las prioridades del gobierno cubano fue desde entonces de fortalecer los lazos bilaterales con China. 
transnacionales y permitieron crear un espacio económico de parte y otra del estrecho de Florida (Hansing y Orozco 2014; Jolivet 2017). En 2009, la administración Obama anunció el levantamiento de restricciones sobre los viajes y las remesas que siempre habían sido limitadas al mínimo durante los mandatos de los Republicanos, y de la Commission for Assistance to a Free Cuba que había sido instaurada por G. W Bush para reforzar el embargo. Obama incrementó la posibilidad de viajar a la isla, a través de licencias individuales que autorizaban a estadounidenses pertenecientes a 12 categorías el pasaje hacia Cuba. En septiembre de 2015, se acelera el proceso de normalización y se levanta el límite del importe de las remesas, los empresarios estadounidenses pueden asociarse con cubanos, vender equipos al sector independiente o privado y abrir oficinas en la isla. Al mismo tiempo, los bancos estadounidenses están autorizados a aceptar cuentas de ciudadanos cubanos fuera de su isla, mientras que las empresas estadounidenses pueden abrir cuentas en Cuba. Y en 2016, después de la visita histórica de Obama a La Habana, se firma la autorización de los viajes comerciales y los viajes de cruceros entre Cuba y Estados Unidos. En las últimas semanas de su segundo mandato el presidente Obama, cumpliendo los términos de las negociaciones con el gobierno cubano, termina con la ley de los "Pies secos/Pies mojados", política que le permitía excepcionalmente a los cubanos que llegaban hacia la tierra estadounidense sin documentos, de obtener al año siguiente la residencia permanente estadounidense. Con esto «se constató una brusca reducción de las salidas ilegales y de forma concomitante se redujeron las ofertas de las ventas de viviendas de las personas que esperaban obtener con ello un capital para financiar el proceso de emigración y de instalación en el nuevo país (Pleyán 2020: 141). Después de su elección, el presidente Trump cambió de forma muy dura la política de los Estados Unidos respecto a Cuba en un momento en que la disminución de los intercambios económicos y de petróleo con Venezuela ya era un golpe grande para la economía del país (Mesa-Lago y Vidal 2019). Además de reafirmar los términos del embargo económico, en particular la Ley HelmsBurton, el gobierno republicano aumentó las restricciones de viajes para los ciudadanos estadounidenses prohibiendo por ejemplo los viajes individuales, el turismo de cruceros y la participación en ciertas transacciones financieras directas (US Embassy 2017). Esas restricciones tuvieron un impacto fuerte en el sector turístico de la Isla, reduciendo el número de turistas proviniendo desde EEUU que había crecido exponencialmente desde 2016, y por lo tanto reduciendo el número de posibles visitantes para las casas particulares como para los hoteles de la capital cubana (Perrelló Cabrera 2019).

La pandemia del Covid-19 supuso posteriormente otro golpe para la economía del turismo en la isla y posiblemente para el sector inmobiliario privado vinculado. 
Este rápido contexto nos permite introducir el ámbito de nuestro análisis del mercado inmobiliario. Por un lado, las reformas hacia una mayor mercantilización y el aumento del sector privado son esenciales para el análisis de los mecanismos de este mercado en formación. Por otro lado, la importancia de las relaciones transnacionales, especialmente a través de los cubano-americanos y la industria turística, aunque presenten grandes variaciones inducidas por las coyunturas geopolíticas y globales, son en nuestra opinión factores importantes que deben mencionarse para analizar nuestros datos y responder a las preguntas de investigación planteadas anteriormente.

\section{Metodología: Acceso a la información y datos sobre el mercado inmobiliario habanero}

\section{Small-big data, producción de datos y digitalización del mercado inmobiliario}

En Cuba, la única forma de conocer el número de transacciones inmobiliarias y su ubicación es tener acceso a la escritura notarial de compraventa. En ella está escrito el precio en pesos cubanos (CUP) sobre el cual se aplica el Impuesto sobre la transmisión de bienes y herencias correspondiente al 4\% del valor referencial, que pagan tanto el comprador como el vendedor. Pero es casi imposible, y más aún para una investigadora extranjera, el tener acceso a esa información. El valor referencial es calculado en acorde al Decreto Ley 343 según propiedades físicas y la ubicación geográfica de la vivienda. No obstante, el valor de mercado de una vivienda puede ser, y lo es a menudo en los municipios centrales de La Habana, más de 10 veces superior al valor referencial oficial (Pleyán 2020). El precio "oficial" proviene de una fórmula de cálculo con constantes fijas aunque el precio del mercado fluctúa constantemente según las mismas propiedades físicas pero también según potencialidades de inversión propias a cada inmueble, políticas nacionales e internacionales y tendencias económicas de los mercados inmobiliarios locales y globales.

La dificultad de obtener información verídica acerca del precio mercantil de la vivienda en Cuba a gran escala con el fin de realizar un análisis cuantitativo de peso nos llevó a analizar los precios anunciados publicados por internet en un contexto de digitalización del mercado inmobiliario (Fields y Rogers 2019), sumándonos a la reciente reflexión sobre el uso de los datos digitales en el contexto del Sur Global (Milan y Treré 2019). A pesar de que nuestros datos se basan en anuncios de venta de propiedades de las cuales no sabemos si se vendieron o no y finalmente a qué precio, los datos recolectados no son arbitrarios y nos permiten acercarnos al precio del mercado. Por medio del webscraping 
(raspado web) se recolectaron cada mes miles de anuncios, particularmente en los cuatro municipios del estudio, totalizando unos 30 mil anuncios, pero muchos de estos anuncios eran duplicados que se mantenían publicados de un mes al otro; por otro lado, eran numerosos los anuncios que no indican al precio de venta o que no disponían de coordenadas geográficas, lo cual era necesario para construir nuestra base de datos ${ }^{5}$. Finalmente, después de filtrar los anuncios nos quedamos con 7075. Simultáneamente, aunque que no usamos la información para este trabajo, también consultamos regularmente otros sitios inmobiliarios o páginas Facebook para comparar los precios con los que hemos estado recaudando.

Las muestras recogidas de 7075 anuncios a lo largo de 5 años (2015-2020) puede parecer pequeña, sobre todo enfocándose en La Habana que concentra más del $80 \%$ del mercado de la isla. Sin embargo, ante la carencia de datos, y como resultado de las reflexiones críticas y feministas en las ciencias de la información geográfica y del procesamiento de datos, coincidimos con la idea de Gieseking sobre el big-small data (2018). En nuestro caso, la inexistencia de este tipo de bases de datos en Cuba valora aún más nuestra muestra. Argumentamos que a pesar de sus limitaciones los datos son suficientemente grandes para su contexto (Gieseking 2017) y tienen un interés científico real si se sitúan en el contexto socio- histórico de producción y recolección de datos sobre la vivienda en Cuba. Desde luego no tenemos más que una visión parcial del número total de ventas inmobiliarias. Tampoco conocemos el precio de venta final de cada transacción, pero en un contexto en el cual esta información no existe, nuestra intención era crear una base de datos cronológica y relativamente amplia. Por lo tanto, nuestros cálculos indican los precios de venta publicados, es decir no el valor de bien inmobiliario a la venta sino una opinión del valor: un potencial.

\section{Selección de sitios web, desarrollo de la base de datos}

Escogimos los sitios web que presentaban la mayor cantidad de anuncios, en los cuales se publicaban de manera constante nuevos anuncios y desde los cuales se facilitaba la extracción de la información necesaria con el método del web scraping. Obtuvimos datos de anuncios principalmente de detrasdelafachada.com, porlalivre.com y espaciocuba.com, además de algunos provenientes de cubahomesdirect.com y havanakeys.com. Después de 2017 desaparecieron los sitios web de espaciocuba, cubahomesdirect y havanakeys y vemos el surgimiento cubisima o de la sección "vivienda" de manera importante en otras plataformas

5 Podemos decir también que solo algunos sitios web indicaban las coordenadas geográficas de cada anuncio, esenciales para nuestros análisis a través de un SIG. 
como revolico.com con gran cantidad de anuncios cada día para La Habana. De cada anuncio se procedió a extraer como mínimo los datos de precio y la ubicación geográfica (con sus coordenadas en longitud y latitud). Además, se obtuvieron en lo posible los datos de: tipo de bien inmobiliario (apartamento o casa), número de habitaciones, número de baños, superficie en $\mathrm{m}^{2}$, piso del apartamento, año de construcción, dirección entre calles, el URL del anuncio y la fecha de publicación. También recolectamos los párrafos descriptivos de la propiedad hechos por cada anunciante.

Entre 2015 y mitad de 2017 toda la información de los anuncios se extrajo manualmente copiando y pegando en una tabla los datos proviniendo de Porlalivre, Cubahomesdirect y Havanakeys. A partir del 2017, además de seguir extrayendo manualmente la información de los anuncios de Porlalivre, pusimos en marcha el web scraping para los sitios web de Detrasdelafachada y Espaciocuba, con información geográfica en coordenadas para cada anuncio, razón por la cual priorizamos estos sitios web. Para nuestra sorpresa, descargamos información de más de 800 antiguos anuncios publicados antes del comienzo de nuestro proyecto entre el 2012 y 2014 que seguían disponibles. El web scraping nos permitió también extender nuestra área de colecta en estos sitios web para abarcar toda la provincia de La Habana, lo cual nos permite desde el 2018 contextualizar mejor la evolución del mercado inmobiliario en los barrios centrales con respecto al resto de la ciudad.

\section{Límites en la metodología}

La base de datos nos permite tener una visión macroscópica de las características y del desarrollo de este mercado a partir de lo que está disponible por internet por lo tanto sólo permite una visión parcial de lo que se anuncia y se vende. Somos conscientes que corresponde a una visión sesgada del mercado inmobiliario total de la ciudad, y la actividad inmobiliaria que da lugar a la movilidad residencial en el terreno es muy superior a los 1.500 anuncios anuales procesados en la base de datos. Una gran parte del mercado se desarrolla aún hoy en día por fuera de las plataformas de internet a través de pancartas de "Se Vende" en las ventanas, a través de la venta en mercados inmobiliarios presenciales o a través de corredores. También se debe mencionar que se mantiene la permuta, acción autorizada legalmente desde el principio de la Revolución para intercambiar vivienda. Sin embargo, como demuestran los trabajos del economista urbano R. Núñez, la permuta, que oficialmente no contiene un intercambio monetario, fue el primer mecanismo que permitió acercarse al valor de cambio de la vivienda y al valor de suelo en Cuba. Antes de la compraventa autorizada en el 2011, la permuta funcionó como 
un instrumento de valoraciones y transacciones ocultas e informales en materia de vivienda, donde los intereses monetarios aparecen como una característica cada vez más importante. [...] las permutas incorporan ahora nuevos aspectos que anticipan futuros incrementos en el valor de la propiedad y otros beneficios y utilidades derivados del desarrollo de negocios en la vivienda, o que anticipan impactos positivos derivados de inversiones públicas o nuevas regulaciones urbanas (Núñez 2012: 91, trad. del inglés)

No sabemos qué parte representan los anuncios de venta inmobiliaria en internet con respecto al conjunto de anuncios del mercado inmobiliario, pero se puede suponer que su importancia está en aumento siguiendo el aumento en acceso a internet de la población cubana (Venegas 2010; Jolivet 2017) y a inversorescompradores en el extranjero. Como todo anuncio inmobiliario, la calidad de este y la veracidad de la información disponible dependen del anunciante.

\section{Calificar la mercantilización de la vivienda en la Habana. ¿Qué se vende, a dónde y a qué precio?}

Según los 7075 anuncios, obtenemos un precio de venta medio para La Habana de 45000 CUC equivalente al US dólar, mientras que el promedio del valor de venta es de 78247 CUC lo cual indica que existen propiedades que se anuncian muy caras, por encima de las demás.

La figura 1 nos permite ver la distribución de frecuencias de los anuncios según el precio cada 5000 CUC. Vemos que la moda de la distribución es de tan

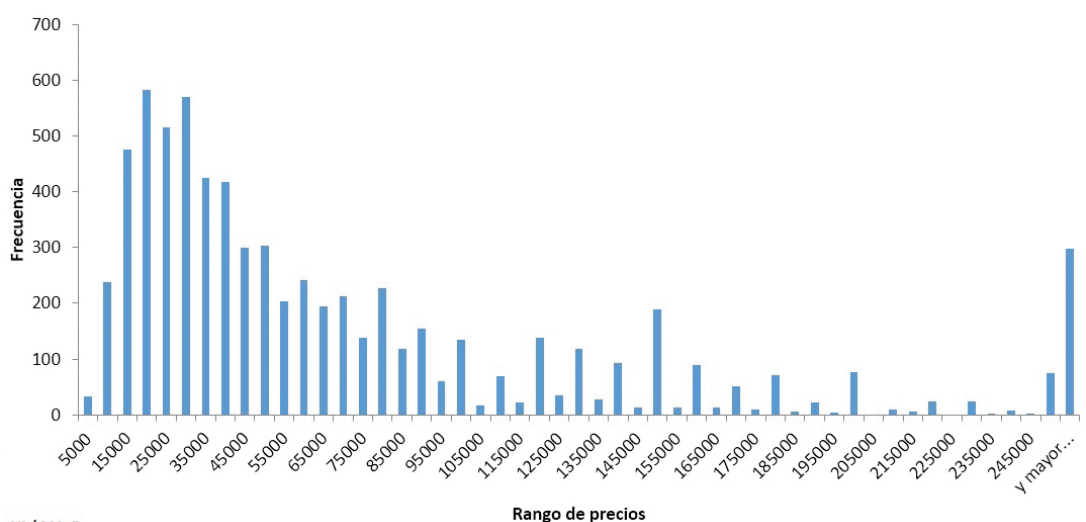

VJ / MA @

Rango de precios

Figura 1 Histograma de número de anuncios según el rango de precios 


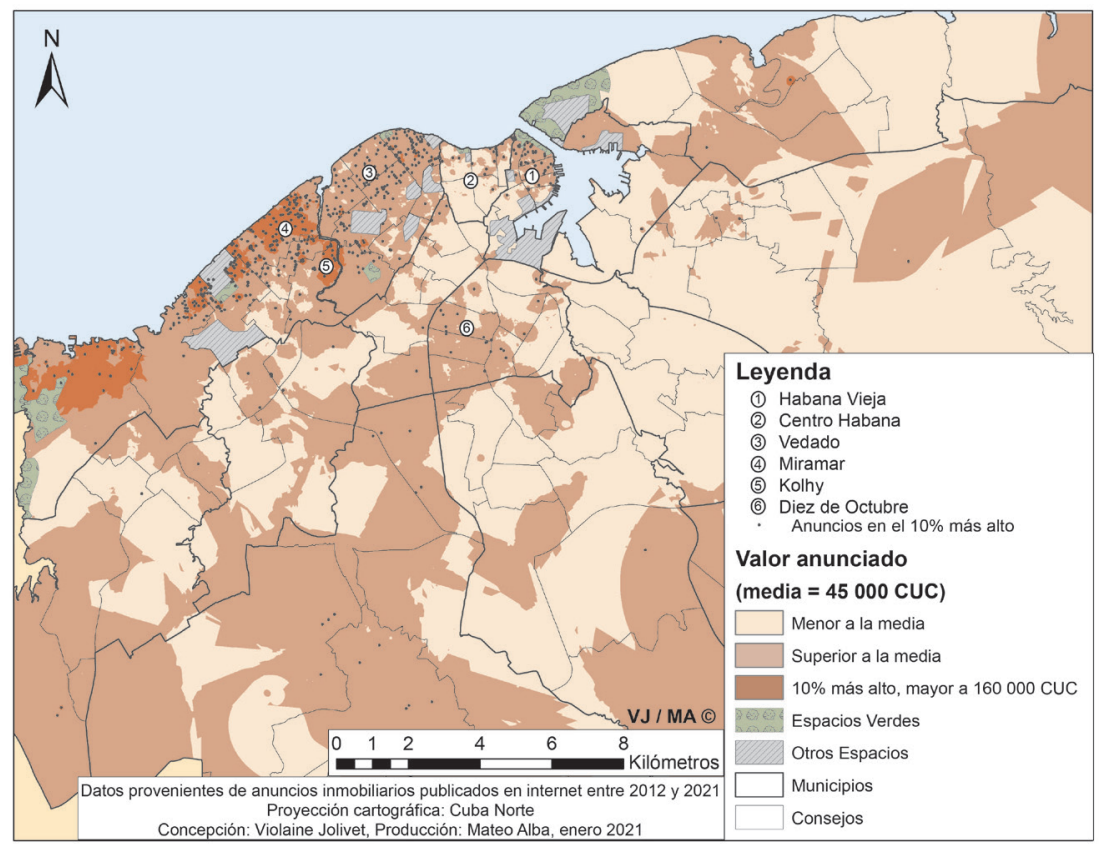

Figura 2 Interpolación de precios según el valor de venta de propiedades anunciadas por internet

solo 20000 CUC. Se constata también que la mayoría de las transacciones de vivienda de La Habana se negocian en un rango de 15000 a 40000 CUC pero que en paralelo la mitad de los anuncios superan los 45000 , y el $10 \%$ de los anuncios tienen un precio superior a 160000 CUC.

El mapa de la figura 2 da evidencia de la diferencia en los bienes raíces a la venta según cada municipio y barrio. Con nuestro enfoque en el centro de la ciudad, se observa claramente que casi toda Plaza de la Revolución y la mayoría de Miramar tienen precios de venta por encima de la media de La Habana y Centro Habana está casi siempre por debajo de la media. Por otro lado, se observa como la zona patrimonial de La Habana Vieja da precios por encima de la media mientras que en el mismo municipio el consejo popular de Jesús María, más adentro de la bahía y rodeado por espacios industriales, está por debajo. En Diez de Octubre, el más poblado de los 15 municipios de La Habana, se observa también cómo gran parte está por debajo de la media mientras que zonas como La Víbora, cuya fundación se remonta a la época colonial, están por encima. Este mapa indica también dónde se sitúa el 10\% de los anuncios más caros recolectados que aparecen en mayor parte en los barrios céntricos y 
qué zonas tienen un precio medio por encima de este precio. Así resaltan los antiguos barrios burgueses donde todavía residen la mayoría de las elites políticas y militares de la ciudad, además de las embajadas extranjeras con propiedades amplias y de alta calidad arquitectónica y técnico-constructiva, como en Miramar y Kolhy.

Se trata en estos casos de una reinversión en las propiedades de los barrios históricamente burgueses después de una época en la que las leyes urbanas del principio de la revolución y el exilio a Miami de las clases altas habían aumentado la mezcla social de estos barrios residenciales. De hecho, la reforma urbana de 1960, que durante mucho tiempo fue el único documento que influyó en el desarrollo urbano de Cuba, ilustró la voluntad de las políticas castristas de reequilibrar el territorio nacional a costa de la ciudad capital (Suman 1987). Además, la longevidad de la Revolución tuvo un impacto colosal en la redefinición de los territorios de La Habana, especialmente a través de la drástica reducción de las funciones comerciales y la distribución "equitativa" de las viviendas, lo que favoreció claramente una "desaburguesación" y una estandarización socioespacial de la ciudad (Eckstein 1977; Slater 1982).

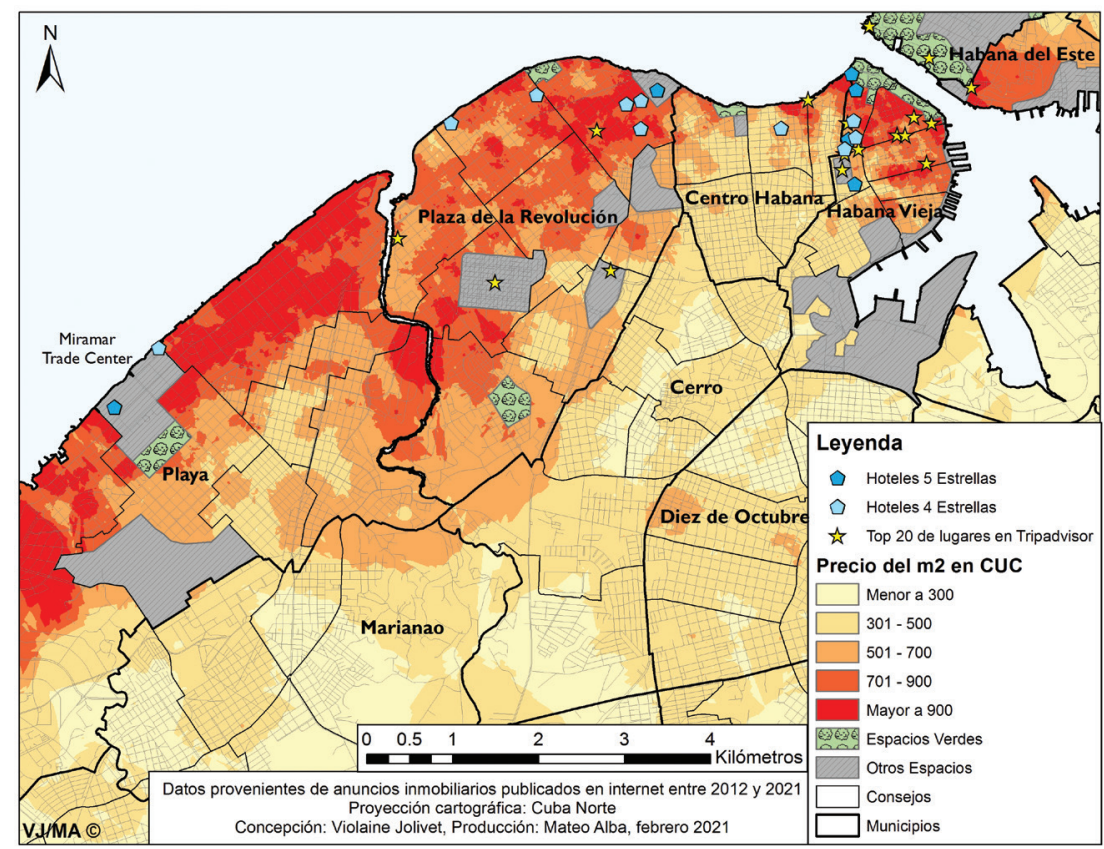

Figura 3 Mapa de interpolación de precios por $\mathrm{m}^{2}$ en La Habana 
Sin embargo, el análisis de los precios de venta como conjunto, si bien permite valorar el papel de la urbanidad de los barrios en los que se encuentra a la escala de la metrópolis, no permite tener una idea más afinada del papel del espacio urbano local en el proceso de reinversión del capital privado en la ciudad. Para poder comparar los precios en los distintos barrios sistematizando los análisis espaciales, es necesario comparar los precios por metro cuadrado en todos los municipios (Figura 3).

El mapeo de los precios por metro cuadrado demuestra cómo sobresalen además de Miramar o Kholy otros barrios, en particular en el Vedado, unas zonas de Centro Habana y la Habana Vieja donde los alojamientos son más pequeños pero también pertenecen en su gran mayoría a la época colonial y moderna. Con esta visualización de la distribución de los precios por metro cuadrado, queda claro que existe un factor centro/periferia en la fijación de los precios de venta y que la reintroducción de un valor de cambio a la vivienda promueve una diferenciación espacial de los precios fuera del valor de uso y de la propiedad del suelo establecido por el Estado. Por tanto, entran en juego las características de ubicación en los precios que genera una renta indirecta y demuestra formas de diferenciación o fragmentación capitalista del espacio urbano. Así, según el estudio de Hammel sobre el rent-gap (1999), cabe suponer que los precios de los barrios céntricos populares y más degradados aumentan debido a la reinversión en ese entorno, lo que ha incrementado el potencial económico de todas las zonas céntricas.

\section{¿Los distritos centrales son los espacios más codiciados? Recapitalización de la centralidad}

Aunque en La Habana la capitalización no consiste en una creciente monopolización de la propiedad por parte de ciertos individuos, sí existe sin embargo una concentración espacial del mercado y por tanto del capital en los distritos centrales de la ciudad.

La Figura 4 muestra la evolución de los precios por metro cuadrado diferenciando los 4 municipios centrales de los demás. La curva discontinua antes de 2015 indica una menor fiabilidad de nuestros datos entre 2012 y 2015 , ya que los datos fueron recuperados a posteriori y son menos numerosos. De manera muy clara se puede observar como los municipios de Plaza de La Revolución y Playa se sitúan siempre por encima de la media de precios de La Habana, mientras que la media de los municipios por fuera de nuestra área de estudio, además de Centro Habana, disminuyen esta media siendo barrios más asequibles y populares. El caso de La Habana Vieja, todavía muy heterogéneo entre una zona híper-turística y sectores muy populares y degradados, presenta una curva más 


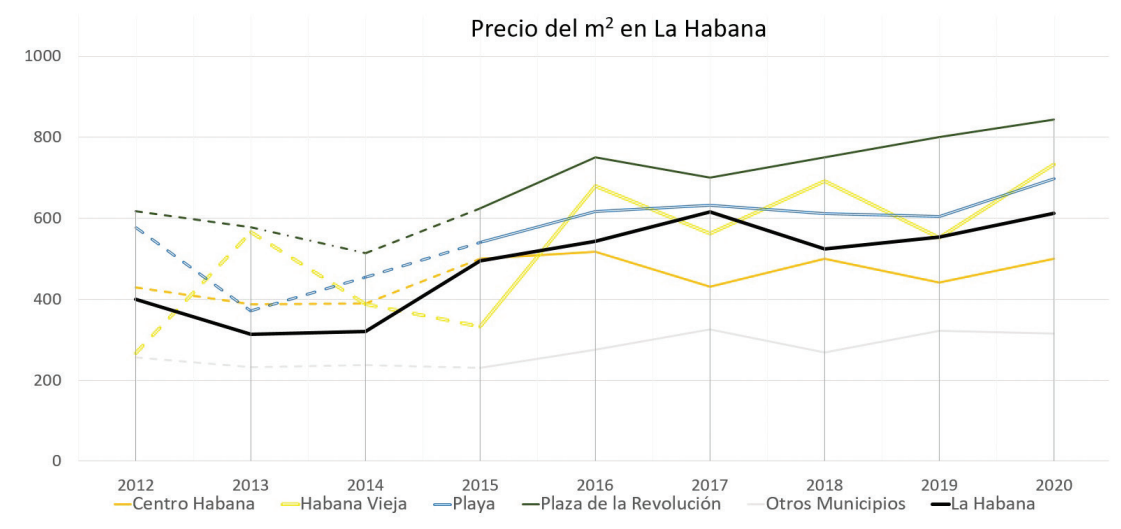

Figura 4 Evolución del precio del m2 en La Habana en CUC

irregular, pero a partir del 2017, los precios por metro cuadrado son superiores a la media de La Habana. La heterogeneidad de los bienes a la venta, su estado y tamaño en cada uno de los municipios centrales influye lógicamente en el precio medio por metro cuadrado. Sin embargo, la centralidad sigue siendo un indicio clave en la caracterización del mercado de La Habana, donde incluso los distritos centrales más populares y degradados tienen precios muy superiores a los demás como lo muestran los datos en el 2020 donde Centro Habana tiene un precio medio de $500 \mathrm{CUC} / \mathrm{m}^{2}$ mientras que el precio medio en los municipios no centrales es de $333 \mathrm{CUC} / \mathrm{m}^{2}$. En comparación los demás municipios centrales tienen precios medios de $696 \mathrm{CUC} / \mathrm{m}^{2}$ en Playa, 756 CUC/m² en Habana Vieja y de $838 \mathrm{CUC} / \mathrm{m}^{2}$ en Plaza de La Revolución.

Otro factor que permite apreciar más formas de reinversión de capital a través de inmuebles en los distritos centrales es la mayor actividad del mercado en estos lugares. En números brutos los municipios de La Habana que tienen el mayor número de anuncios son Plaza, Playa y Diez de Octubre. De hecho, en 2020 el solo municipio de Plaza de La Revolución contiene el 21,9\% de todos los anuncios de La Habana. Los cuatro municipios que estudiamos comprenden el 54,2\% de todos los anuncios de La Habana en un espacio que ocupa el 7,7\% de la provincia y donde vive el $25,9 \%$ de su población. Estos municipios centrales de La Habana dominan el mercado inmobiliario de la capital y del país lo cual nos permite identificar rent-gaps que se cierran (Smith 1979). Aunque, la fase de reinversión en la que se encuentra La Habana actualmente está lejos en escala e intensidad de las metrópolis del Norte Global que dominan el 
panorama académico en estos estudios, parece que esa concentración de la oferta y la mayor mercantilización de la vivienda en los distritos centrales se debe en parte al mayor valor potencial de los inmuebles en estos distritos y a la especulación, lo cual es una característica común que tienen con zonas de reinversión de ciudades del Norte. La visión del rent-gap permite entender las diferencias de precio y actividad del mercado dentro de nuestra base de datos destacando a los barrios céntricos como los principales receptores de la inversión inmobiliaria.

\section{Turistificación de La Habana y mercantilización de la vivienda: la perspectiva transnacional del mercado habanero}

En esta una última parte, nos parece importante no limitar el análisis de la reinversión a un enfoque espacializador de la centralidad urbana, sino también centrarse en la dimensión más relacional del espacio urbano como factor explicativo de la distribución de los precios. Aquí consideraremos el papel de los flujos transnacionales del capitalismo y, en particular, el turismo y las remesas que forman una de las fuentes principales de divisas en el país desde los 90. Los espacios que caracterizan esta reconexión con los flujos del capitalismo global son lugares marcados por una arquitectura diferenciada, pero también son espacios que orientan a la ciudad hacia el mercado y por lo tanto transforman la centralidad urbana en una centralidad capitalista y turística. Estas mismas zonas pueden ser espacios urbanos en los que el Estado, en asociación con firmas extranjeras, reinvierte en la ciudad para atraer flujos financieros, señas de una metropolización que se ha iniciado en esta aglomeración importante del Caribe y cuya fragmentación del espacio por el mercado comienzan a verse más claramente en el paisaje urbano. Como ejemplos se pueden mencionar el Centro de Negocios Miramar construido a partir del 1999 y los grandes hoteles de cuatro o cinco estrellas (Figura 5) que han florecido en los últimos años que favorecen el desembarco de flujos de capital extranjero en áreas que luego se convierten en zonas de inversión y permiten considerar el papel del Estado en la capitalización del espacio urbano (Hackworth y Smith 2001, LópezMorales 2019).

Como lo demuestra nuestro análisis de los precios por metro cuadrado, la mayoría de los grandes hoteles y zonas de concentración y de inversión del turismo internacional identificados en la plataforma Tripadvisor están rodeados de manera casi sistemática por las zonas con los precios más altos, por encima de $700 \mathrm{CUC} / \mathrm{m}^{2}$ (Figura 3). Esto es particularmente visible en el tercio norte de La Habana Vieja, descrito como un hyper-centro turístico y donde el proceso de 


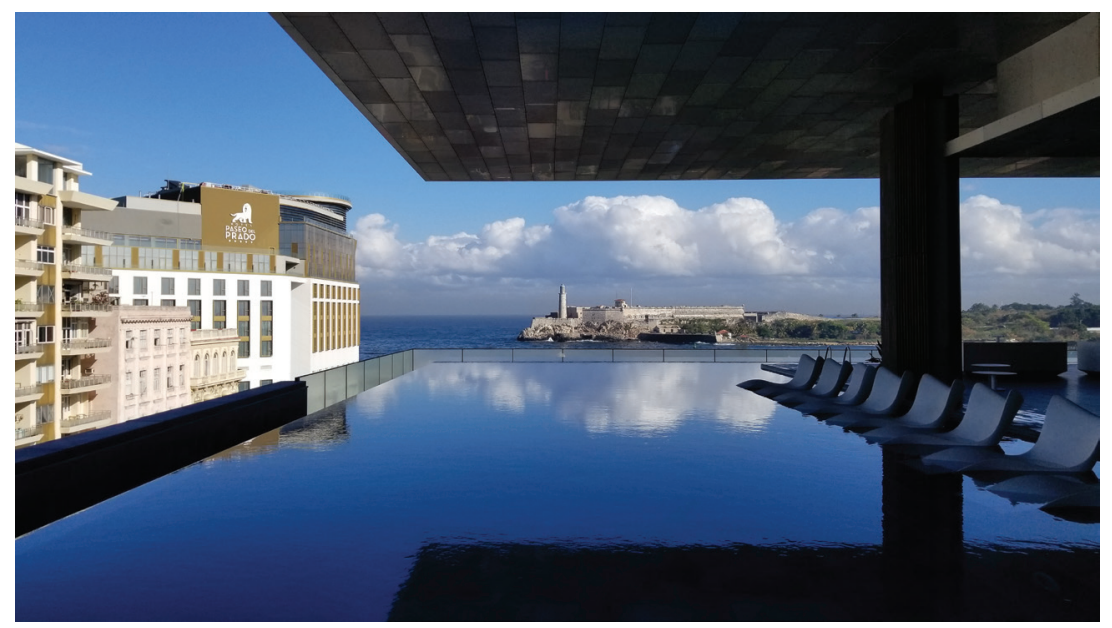

Figura 5 Hotel 5* Paseo del Prado desde la piscina del Iberostar Grand Packard. Habana Vieja, 2020 (C) Violaine Jolivet

recapitalización por parte del Estado a través de la etiqueta de Patrimonio Mundial ya había comenzado desde la década del 2000 (Rutheiser 2000; Bailey 2008). Estas zonas de recapitalización, a través del turismo y las opciones de desarrollo económico del Estado, influyen entonces en el atractivo que tienen las manzanas circundantes, pero también son una forma de asegurar el valor potencial de estas áreas en el mercado inmobiliario, en particular a través de formas de mantenimiento y control de los espacios públicos o a veces de un suministro de agua o electricidad más estable.

Finalmente, uno de los últimos factores que parece imprescindible tener en cuenta a la hora de analizar los precios de los inmuebles en los distritos centrales, es la potencialidad de la transformación de la vivienda en una mercancía a través de su uso, especialmente en el caso de los restaurantes privados (Henken y Vignoli 2017) o, más usualmente como sitio de alquiler para turistas (casas particulares). La mercantilización de la vivienda favorece la transformación de numerosas propiedades en "propiedades turísticas", donde los que tienen dinero de sobra para invertir pueden aprovechar el rent-gap (Wijburg et al. 2020, trad. inglés). Así, la posibilidad de sacar provecho de la vivienda ejerciendo una actividad económica fuera del sector estatal o de forma transnacional es uno de los elementos esenciales para entender este mercado. Es evidente que la inversión inmobiliaria también está vinculada a formas de mercantilización de la vivienda, pues su valor ya no se basa únicamente en sus características intrínsecas sino 


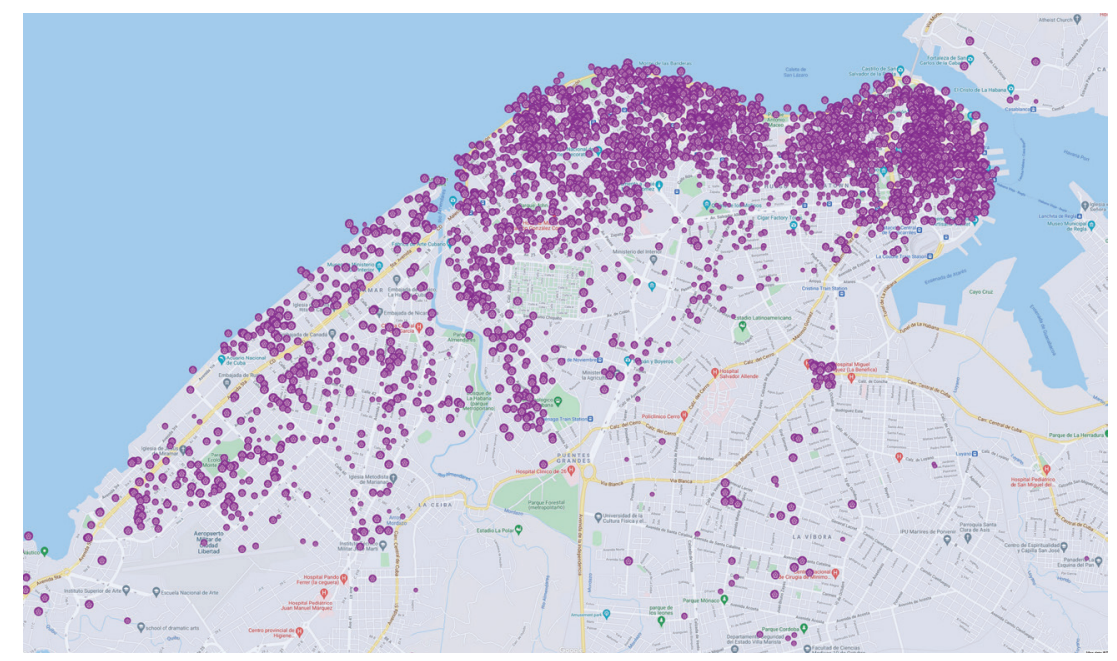

Figura 6 Localización de viviendas completas disponibles para el alquiler temporal según la base de datos RDNA de Airbnb, febrero 2021

también en la posibilidad de beneficiarse monetariamente de ella, especialmente en el contexto del crecimiento del turismo urbano en La Habana y del crecimiento del trabajo por cuenta propia. La conexión de este mercado de propiedad turística con las remesas y otras formas de inversión de extranjeros permiten también resaltar formas de gentrificación transnacional y la conversión de la vivienda en Cuba en activos financieros (Pleyán 2020; Wijburg et al. 2020) que confirman la afirmación del peso de la centralidad de La Habana a escala regional y mundial.

Una mirada a la base de datos de Airbnb (Figura 6), autorizado en Cuba desde el 2015, muestra la importancia de este proceso de transformación de la vivienda en mercancía para la extracción de renta y el gran aumento del número de habitaciones o viviendas enteras ya no destinadas a los habitantes de la ciudad, sino a los turistas o visitantes extranjeros, sean o no miembros de familias transnacionales cubanas, que a menudo contribuyen a la compra, pero también al amueblamiento y la gestión de estos bienes raíces a través de las plataformas digitalizadas de alquiler. No obstante, esta gentrificación turística y mercantilización de la vivienda llevó a un aumento de las restricciones en torno a la permuta, donaciones, compraventa y construcción de viviendas en "zonas de alta significación para el turismo", esto según la resolución 133 de la ley de la vivienda en Julio 2018 aplicada en los municipios de Centro Habana y Habana Vieja para "mantener el equilibrio de la población residente y evitar su incremento" (Gaceta Oficial 2018). 


\section{Conclusión}

Nuestro análisis de los precios de compra/venta y su distribución entre 2012 y 2020 nos ha permitido destacar primero, un crecimiento constante de los precios por metro cuadrado en toda La Habana, a pesar de los efectos del contexto cubano, una inversión inmobiliaria más activa en los barrios céntricos con los precios más altos del mercado y un mayor número de inmuebles en venta. La altura de los precios a la venta, comparativamente con los otros municipios, permite suponer que los barrios centrales se han vuelto selectivos para aquellos grupos capaces de invertir en ellos - cuentapropistas, familias transnacionales o extranjeros con testaferros -, lo cual significa que a través del mercado la vivienda ha aumentado su valor de cambio y que su valor de uso se adapta a las exigencias de la mercantilización de la vivienda. Aunque no lo hayamos analizado, la valorización monetaria más alta de la vivienda en los barrios céntricos va probablemente a contribuir al desplazamiento de hogares más humildes hacia otros municipios de la ciudad donde los precios son más asequibles. Esta concentración del mercado en las zonas céntricas ha permitido distinguir formas de gentrificación inducidas por lógicas de inversión, sobre todo porque el valor potencial de estos inmuebles, enlazados a su centralidad, permite prever un mayor retorno de la inversión para los compradores. Nuestra investigación exploratoria del mercado digitalizado permite así presentar un caso singular de gentrificación emergente en un área donde no se ha estudiado el tema. Este artículo proporciona también datos inéditos que, aunque escasos, se inscriben en el paradigma del small big data, y permiten informar sobre la evolución del mercado inmobiliario habanero y la mercantilización de la vivienda en la capital socialista.

Segundo, nuestro análisis también nos ha permitido leer los efectos de las divisiones geográficas que trae consigo este nuevo ciclo de inversión inmobiliaria, así como la fragmentación del espacio urbano para la venta y la compra (Lefebvre 1991). Esta fragmentación es todavía incipiente en el espacio urbano de La Habana, pero se está produciendo a través del desarrollo de espacio destinado esencialmente al turismo, y del anclaje de los flujos de capital transnacional, siendo ambos procesos concomitantes. Sin embargo, la juventud del mercado inmobiliario y la abolición de la especulación inmobiliaria durante más de cincuenta años en este Estado socialista requiere un manejo cuidadoso del concepto de gentrificación y del diferencial de la renta del suelo. Si bien es cierto que una ciudad elitista se abre paso en las calles habaneras de los barrios céntricos, el espacio urbano, en gran medida controlado y vigilado por el Estado, no es objeto de una monopolización por parte de los intereses privados sino sólo de una mercantilización de la vivienda. También queremos recordar que estos procesos son sólo una parte del mercado inmobiliario donde los inversores locales, así cuenten 
con poco capital, también son importantes. Este mercado se mantiene joven y en evolución constante entre liberalización y regulación estatal. En este sentido coincidimos con las recomendaciones de Carlos García Pleyán (2020) sobre la necesidad de actualizar y publicitar los datos catastrales y de reforzar los instrumentos de control por parte de la municipalidad y la provincia de La Habana sobre las transformaciones edificatorias en curso, así como de mantener estrictas leyes de limitación de la multipropiedad.

Finalizando el artículo en plena pandemia del Covid-19 y después de la reunificación monetaria en Cuba, planteamos dos fenómenos que emergieron en los anuncios recolectados durante los últimos meses y que nos parecen importantes para analizar los mecanismos que impulsan la mercantilización futura de la vivienda:

1). La transformación de la vivienda en activos financieros no sólo es el resultado de una transnacionalización del mercado, sino es también una práctica que emerge entre los compradores cubanos que temen a la inflación tras la reunificación monetaria y, por lo tanto, inmovilizaron su dinero en una propiedad en un contexto de gran desconfianza hacia el sistema bancario nacionalizado.

2). La importancia de los vínculos transnacionales (incluyendo el turismo) en la mercantilización de la vivienda hace más inestable y heterogénea la recapitalización del espacio urbano y la transformación de la vivienda en mercancía. Prueba de ello es la rápida venta, a veces a precios inferiores a los observados a principios de 2020 en nuestra base de datos, de varias viviendas turísticas que se han vaciado por la pandemia.

\section{Reconocimientos}

Los autores agradecen los comentarios y revisiones de Matari Pierre y Ernesto López-Morales, así como a los revisores anónimos de la revista por sus relevantes aportaciones a esta versión del artículo. Queremos también agradecer calurosamente a Leslie Carmichael por sur ayuda en la traducción del artículo en inglés y a Jeimy Arias por su relectura en español.

\section{Bibliografía}

Aalbers, M. (2019) "Introduction to the forum: From third to fifth-wave gentrification”, Tijdschrift voor Economische en Sociale Geografie, 110(1): 1-11. https://doi. org/10.1111/tesg.12332.

Andrusz, G., Harloe, M., y Szelenyi, I. (2011) Cities After Socialism: Urban and Regional Change and Conflict in Post-Socialist Societies. Hoboken, NJ: John Wiley \& Sons. 
Bailey, N. (2008) “The challenge and response to global tourism in the post-modern era: The commodification, reconfiguration and mutual transformation of Habana Vieja, Cuba", Urban Studies, 45(5-6): 1079-96. https://doi.org/10.1177/0042098008089854.

Bastian, H. (2018) Everyday Adjustments in Havana: Economic Reforms, Mobility, and Emerging Inequalities. Lanham, MD: Rowman \& Littlefield.

Bobes, V., Mesa-Lago, C., Chaguaceda, A., Geoffray, M., Alfonso, H., y Rojas, R. (2015) Cuba: ¿Ajuste o transición? Impacto de la reforma en el contexto del restablecimiento de las relaciones con Estados Unidos. Mexico: FLACSO.

Brenner, P., Jiménez, M., Kirk, J., y LeoGrande, W. (2014) A Contemporary Cuba Reader: The Revolution under Raúl Castro. Lanham, MD: Rowman \& Littlefield.

Eckstein, S. (1977) “The debourgeoisement of Cuban cities”, in Louis Horowitz (ed.), Cuban Communism. New Brunswick, NJ: Transaction Books, 445-63.

Edge, K., Scarpaci, J., y Woofter, H. (2006) “Mapping and designing Havana: Republican, socialist and global spaces", Cities, 23(2): 85-98.

Fields, D., y Rogers, D. (2019) “Towards a critical housing studies research agenda on platform real estate", Housing, Theory and Society, 1-23.

French, R., y Hamilton, F. (1979) The Socialist City: Spatial Structure and Urban Policy. Chichester: John Wiley \& Sons.

Gaceta Oficial (2018). Ley General de la Vivienda 2018, resolución 133.

Gieseking, J. (2017) "Size matters to lesbians too: Queer feminist interventions into the scale of big data”, The Professional Geographer, 70(1): 150-6. https://doi.org/10.108 0/00330124.2017.1326084.

Gravari-Barbas, M., y Guinand, S. (eds) (2017) Tourism and Gentrification in Contemporary Metropolises: International Perspectives. Abingdon: Taylor \& Francis.

Hackworth, J., y Smith, N. (2001) “The changing state of gentrification”, Tijdschrift voor Economische en Sociale Geografie, 92(4): 464-77. https://doi.org/10.1111/14679663.00172.

Hamberg, J. (2012) "Cuba opens to private housing but preserves housing rights", The Environment, 19(1): 6.

Hammel, D. (1999) "Gentrification and land rent: A historical view of the rent gap in Minneapolis”, Urban Geography, 20: 116-45.

Hansing, K., y Orozco, M. (2014) “The role and impact of remittances on small business development during Cuba's current economic reforms”, Desigualdades, 69. http:// dx.doi.org/10.17169/refubium-23425.

Harvey, D. (2001) Spaces of Capital: Towards a Critical Geography. Abingdon: Routledge.

Henken, T., y Vignoli, G. (2017) "A taste of capitalism? Competing notions of Cuban entrepreneurship in Havana's Paladares”, Human Geography, 10(3): 97-114. https:// doi.org/10.1177/194277861701000308.

Herrero, G.P. (2007). "Crisis, posmodernidad y planificación estratégica en La Habana”, Anales de geografía de la Universidad Complutense de Madrid (Vol. 27, No. 2, p. 135).

Hill, M. (2007) "Reimagining Old Havana: World heritage and the production of scale in late socialist Cuba", in Saskia Sassen (ed.), Deciphering the Global: Its Scales, Spaces and Subjects. New York: Routledge, 59-78.

Hirt, S. (2013) "Whatever happened to the (post)socialist city?", Cities, 32: 29-38. 
Holbraad, M. (2017) "Money and the morality of commensuration: Currencies of poverty in post-Soviet Cuba", Social Analysis, 61(4): 81-97. https://doi.org/10.3167/ sa.2017.610406.

Iñiguez, L. (ed.) (2014) Las tantas Habanas . . .: estrategias para comprender sus dinámicas sociales. La Habana: Editorial UH.

Jiménez Enoa, A. (2019) “China: el nuevo benefactor de Cuba”, Diálogo Chino. Accessed at: https://dialogochino.net/es/comercio-y-inversiones-es/31432-china-el-nuevo-benefactor-de-cuba/.

Jolivet, V. (2017) "Nouvelles mobilités à Cuba : Penser l'espace relationnel cubain à l'heure du rétablissement des liens avec les États-Unis", Cahiers des Amériques latines, 84: 49-67.

Kubeš, J., y Kovács, Z. (2020) “The kaleidoscope of gentrification in post-socialist cities”, Urban Studies, 57(13): 2591-2611. https://doi.org/10.1177/0042098019889257.

Lees, L., Shin, H., y López-Morales, E. (2016) Planetary Gentrification. Cambridge: Polity Press.

Lefebvre, H. (1991) Le droit à la ville. Paris: Anthropos.

Ley, D. (1996) The New Middle Class and the Remaking of the Central City. Oxford: Oxford University Press.

Lopes de Souza, M. (2016) "Gentrification in Latin America: Some notes on unity in diversity”, Urban Geography, 37(8): 1235-44.

López-Morales, E. (2015) “Gentrification in the global South”, City, 19(4): 564-73. DOI: 10.1080/13604813.2015.1051746.

López-Morales, E., Shin, H., y Lees, L. (2016) “Latin American Gentrifications”, Urban Geography, 37(8). https://doi.org/10.02723638.2016.1200335.

López-Morales, E. (2019), “State-Led Gentrification” in The Wiley-Blackwell Encyclopedia of Urban and Regional Studies https://doi.org/10.1002/9781118568446. eurs0321

Maloutas, Thomas (2017) “Travelling concepts and universal particularisms: A reappraisal of gentrification's global reach”, European Urban and Regional Studies, May. https://doi.org/10.1177/0969776417709547.

Mesa-Lago, C. (2013) "Panorama de las reformas económico-sociales y sus efectos en Cuba", Cuba in Transition (Association for the Study of the Cuban Economy), 23: $1-15$.

Mesa-Lago, C. (2017) “La vivienda en Cuba socialista y las reformas estructurales”, Cuba Posible. https://cubaposible.com/vivienda-cuba-socialismo-reformas/.

Mesa-Lago, C., y Vidal, P. (2019) “El impacto en la economía cubana de la crisis venezolana y de las políticas de Donald Trump.” Real Instituto Elcano, DT, 9.

Milan, S., y Treré, E. (2019) "Big data from the South(s): Beyond data universalism", TelevisionandNewMedia,20(4):319-35.https://doi.org/10.1177/1527476419837739.

Núñez, R. (2008) "La Permuta: An effective instrument for housing transactions in Cuba”, IHS Working Papers, 19.

Núñez, R. (2012) “Urban land management in Cuba”, PhD diss., Utrecht: Uitgeverij Digitalis.

ONEI (2017) "Datos de la Provincia de La Habana”, Anuarios Estadísticos Municipales. Accessed 25 February 2021. http://www.onei.gob.cu/?q=mapa/provincia/habana. 
ONEI (2020) Salario Medio en Cifras Cuba 2019. http://www.onei.gob.cu/sites/default/ files/salario_medio_2019_completa.pdf

Pérez, L. (2014) Cuba: Between Reform and Revolution. Oxford: Oxford University Press. Perrelló Cabrera, J. (2019) "El turismo en Cuba: cambios y tendencias”, Cuba Horinzonte. https://horizontecubano.law.columbia.edu/content/el-turismo-en-cuba-cambios-ytendencias.

Pleyán, C. (2020) "El mercado inmobiliario en cuba: Carencias legislativas y tributarias The real estate market in Cuba: Legislative and tax deficiencies", International Journal of Cuban Studies, 12(1): 135-48. https://doi.org/10.13169/intejcubastud.12.1.0135.

Rabinovich, A. (2010) "Los intereses sectoriales de la vivienda social en Cuba”, EchoGéo, 12.

Rego, R. (2018) “La Habana, dinámica socio espacial de las formas urbanas”, PatryTer, 1: 1-12.

Robinson, J. (2002) "Global and world cities: A view from off the map", International Journal of Urban and Regional Research, 26(3): 531-54. https://doi.org/10.1111/14682427.00397.

Rudolph, R., y Brade, I. (2005) "Moscow: Processes of restructuring in the post-Soviet metropolitan periphery”, Cities, 22(2): 135-50.

Rutheiser, C. (2000) "Capitalizing on Havana: The return of the repressed in a late socialist city", in G. Brudge and S. Watson (eds), A Companion to the City. Oxford: Blackwell, 224-36.

Sánchez Egozcue, J., y Triana, J. (2008) “Un panorama actual de la Economía Cubana, las transformaciones en curso y sus retos perspectivos”, Boletín Elcano, 104: 45.

Scarpaci, J. (2000) "Reshaping Habana Vieja: Revitalization, historic preservation, and restructuring in the socialist city", Urban Geography, 21(8): 724-44.

Scarpaci, J., Segre, R., y Coyula, M. (2002) Havana: Two Faces of the Antillean Metropolis. Chapel Hill, NC: UNC Press.

Shin, H., Lees, L., y López-Morales, E. (2016) "Introduction: Locating gentrification in the global east”, Urban Studies, 53(3): 455-70.

Slater, D. (1982) "State and territory in post-revolutionary Cuba: Some critical reflections on the development of spatial policy", International Journal of Urban and Regional Research, 6(1): 1-34.

Slater, T. (2017) "Planetary rent gaps", Antipode, 49: 114-37.

Smith, N. (1979) "Toward a theory of gentrification: A back to the city movement by capital, not people", Journal of the American Planning Association, 45(4): 538-48.

Smith, N. (1987) "Gentrification and the rent gap", Annals of the Association of American Geographers, 77(3): 462-5.

Smith, N. (2002) "New globalism, new urbanism: Gentrification as global urban strategy”, Antipode, 34(3): 427-50.

Stanilov, K. (ed.) (2007) The Post-Socialist City. Urban Form and Space Transformations in Central and Eastern Europe after Socialism, 92. Berlin: Springer Science \& Business Media.

Suman, P. (1987) "Spatial equality in Cuba", International Journal of Urban and Regional Research, 11(2): 218-42.

Sýkora, L. (2009) "New socio-spatial formations: Places of residential segregation and separation in Czechia", Tijdschrift voor Economische en Sociale Geografie, 100(4): 417-35. 
Szelenyi, I. (1996) "Cities under socialism - and after", in Cities After socialism: Urban and Regional Change and Conflict in Post-Socialist Societies. Hoboken, NJ: John Wiley \& Sons.

Trefftz, E. (2011) "50 años de la ley de reforma urbana en Cuba. En el aniversario del cambio de paradigma”, Revista INVI, 26(72): 19-62. https://doi.org/10.4067/invi. v26i72.558.

Triana, J. (2012) "Cuba: ¿de la "actualización” del modelo económico al desarrollo?” Nueva Sociedad, Democracia y Política en América Latina, 242: 82-91. https://nuso. org/articulo/cuba-de-la-actualizacion-del-modelo-economico-al-desarrollo/

US Embassy in Cuba (2017) "Hoja informativa sobre la política respecto a Cuba", Embajada de los Estados Unidos en Cuba, 17 June. https://cu.usembassy.gov/es/hojainformativa-sobre-la-politica-respecto-cuba/.

Venegas, C. (2010) Digital Dilemmas: The State, the Individual, and Digital Media in Cuba. New Brunswick, NJ: Rutgers University Press.

Vidal, Pavel (2016) “Cuba's Reform and Economic Growth: A Comparative Perspective with Vietnam”, Journal of Economic Policy Reform, 19(2): 148-65. https://doi.org/1 0.1080/17487870.2015.1119046.

Whitehead, L., y Hoffman B. (eds) (2016) Debating Cuban Exceptionalism. Berlin: Springer.

Wijburg, G., Aalbers, M., y Bono, F. (2020) "Cuban migrants and the making of Havana's property market”, Urban Geography, 1: 1-26.

Zhou, M., y Logan, J. (1996) "Market transition and the commodification of housing in urban China", International Journal of Urban and Regional Research, 20(3): 400-21. https://doi.org/10.1111/j.1468-2427.1996.tb00325.x. 